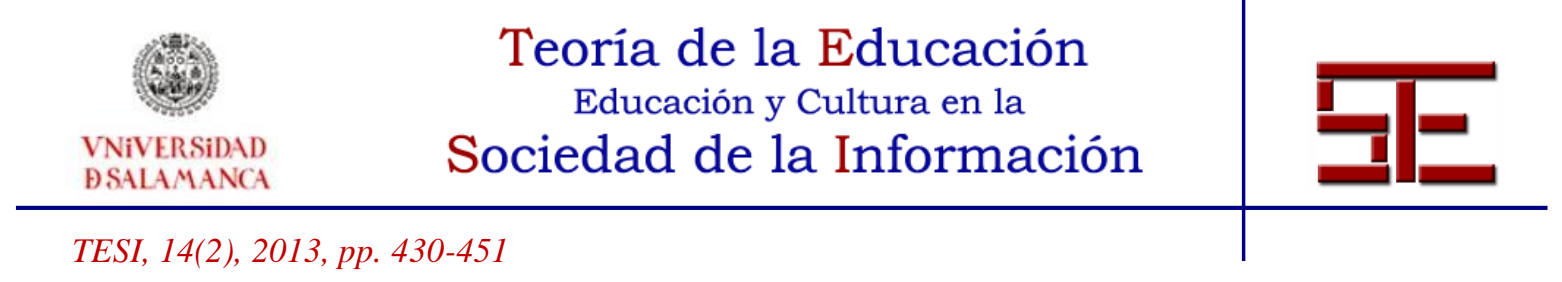

\title{
APRENDIZAJE SOBRE INTERVALOS DE CONFIANZA CON EL SOFTWARE $\mathbf{R}$
}

Resumen: Este trabajo ha consistido en estudiar la viabilidad de la implementación de un método de enseñanza que, en la asignatura de Matemática Computacional, involucra a los estudiantes y profesores a través del uso del software estadístico R para el desarrollo de un trabajo práctico como fortalecimiento de las clases tradicionales. La inferencia estadística, es decir, la determinación de los intervalos de confianza, fue el contenido seleccionado para esta experiencia. Se pretendía mostrar, en primer lugar, que es posible promover, a través de la metodología propuesta, la adquisición de las competencias básicas de inferencia estadística y promover las relaciones positivas entre maestros y estudiantes. También se presenta un estudio comparativo entre las metodologías utilizadas y sus resultados cuantitativos y cualitativos en dos años escolares consecutivos, involucrando varios indicadores. Los datos utilizados en el estudio fueron obtenidos a partir de 1) las respuestas de los estudiantes a las preguntas del examen en los años 2010/2011 y 2011/2012, 2) la realización de un grupo de trabajo en 2011/2012 y 3) a través de las respuestas a un cuestionario (opcional y anónimo) que también aplicó en 2011/2012. En términos de resultados, se destaca el mejor rendimiento de los estudiantes en las preguntas de examen en 2011/2012, que fue el curso en el que los estudiantes utilizaron el software $\mathrm{R}$, y la perspectiva muy favorable de los estudiantes sobre el uso de software R.

Palabras clave: Enseñanza y Aprendizaje; Inferencia Estadística; Intervalos de confianza; Software R; Educación Superior.

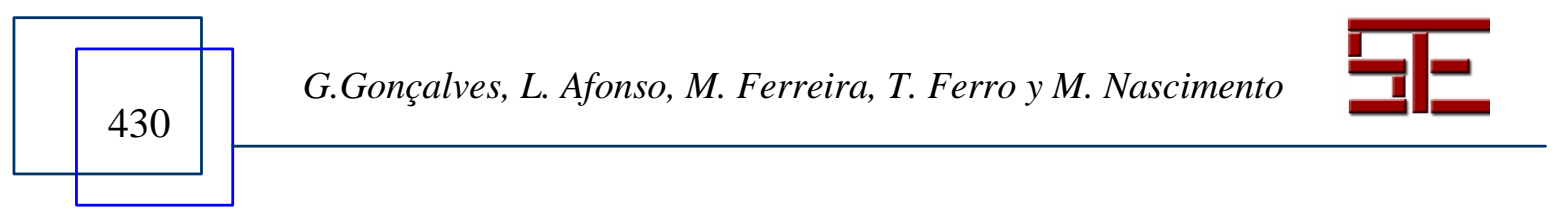




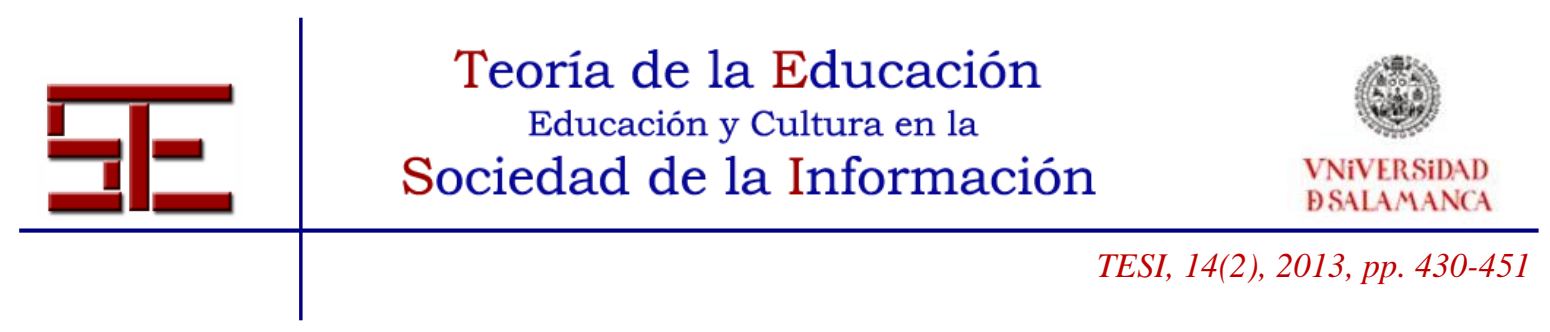

\section{A APRENDIZAGEM SOBRE INTERVALOS DE CONFIANÇA COM RECURSO AO SOFTWARE $R$}

Resumo: Este trabalho consistiu no estudo da viabilidade da implementação de uma metodologia de ensino, na unidade curricular Matemática Computacional, envolvendo alunos e docentes através da utilização do software de estatística $\mathrm{R}$ na realização de um trabalho prático, como reforço do ensino tradicional. A inferência estatística, nomeadamente a determinação de intervalos de confiança foi o conteúdo selecionado para esta experiência. Pretendeu-se, por um lado, mostrar que é possível favorecer, por intermédio da referida metodologia, a aquisição das competências fundamentais na inferência estatística e, por outro lado, promover sinergias entre docentes e alunos. Apresenta-se também um estudo comparativo entre as metodologias utilizadas e respectivos resultados quantitativos e qualitativos em dois anos letivos consecutivos, relativamente a vários indicadores. Os dados usados no estudo foram obtidos através das respostas dos alunos às questões dos exames de 2010/2011 e 2011/2012, da realização de um trabalho de grupo em 2011/2012 e das respostas a um questionário (facultativo e anónimo) também aplicado em 2011/2012. Em termos de resultados, salienta-se um melhor desempenho dos alunos nas questões de exame em 2011/2012, ano que os alunos usaram o software $\mathrm{R}$, e uma perspetiva muito favorável dos alunos sobre a utilização do software R.

Palavras chave: Ensino e Aprendizagem da Estatística; Inferência; Intervalos de Confiança; Software R; Ensino Superior.

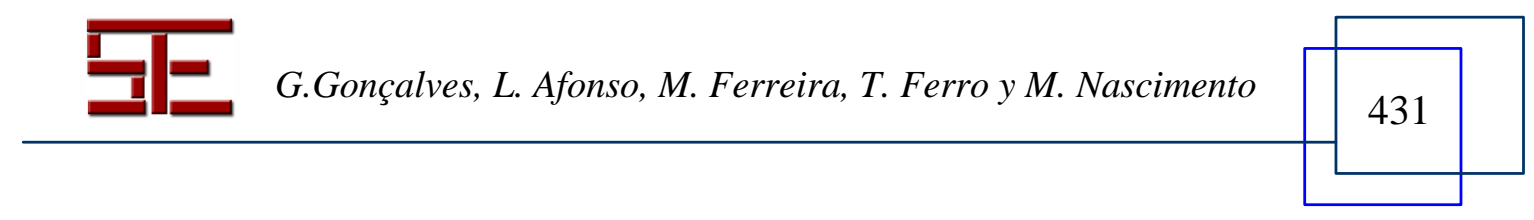




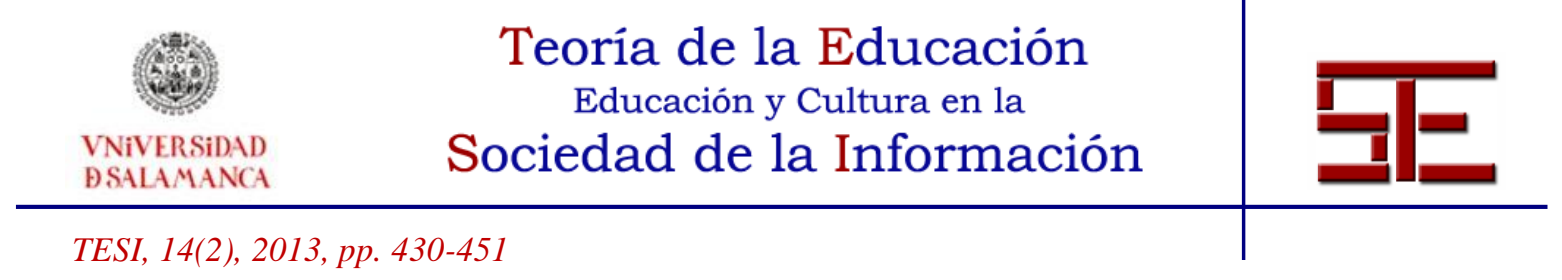

\title{
LEARNING ABOUT CONFIDENCE INTERVALS WITH SOFTWARE R
}

\begin{abstract}
This work was to study the feasibility of implementing a teaching method that employs software, in a Computational Mathematics course, involving students and teachers through the use of the statistical software $\mathrm{R}$ in carrying out practical work, such as strengthening the traditional teaching. The statistical inference, namely the determination of confidence intervals, was the content selected for this experience. It was intended show, first of all, that it is possible to promote, through the proposal methodology, the acquisition of basic skills in statistical inference and to promote the positive relationships between teachers and students. It presents also a comparative study between the methodologies used and their quantitative and qualitative results on two consecutive school years, in several indicators. The data used in the study were obtained from the students to the exam questions in the years 2010/2011 and 2011/2012, from the achievement of a working group in 2011/2012 and via the responses to a questionnaire (optional and anonymous) also applied in 2011 / 2012. In terms of results, we emphasize a better performance of students in the examination questions in 2011/2012, the year that students used the software R, and a very favorable student's perspective about the use of software R.
\end{abstract}

Key words: Teaching and Learning Statistics; Inference; Confidence Intervals; Software R; Higher Education.

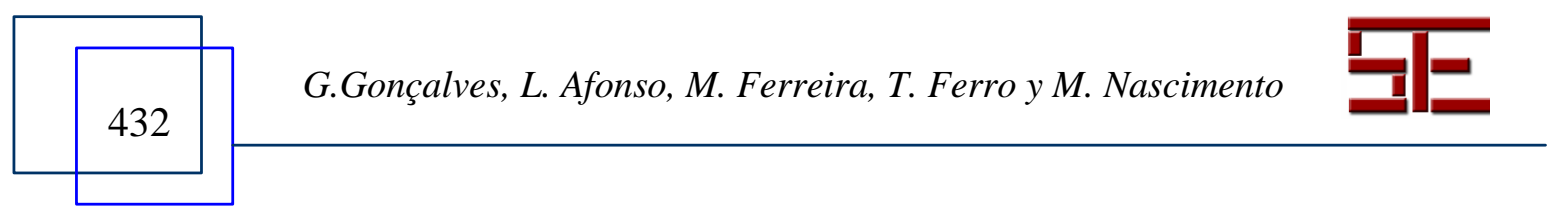




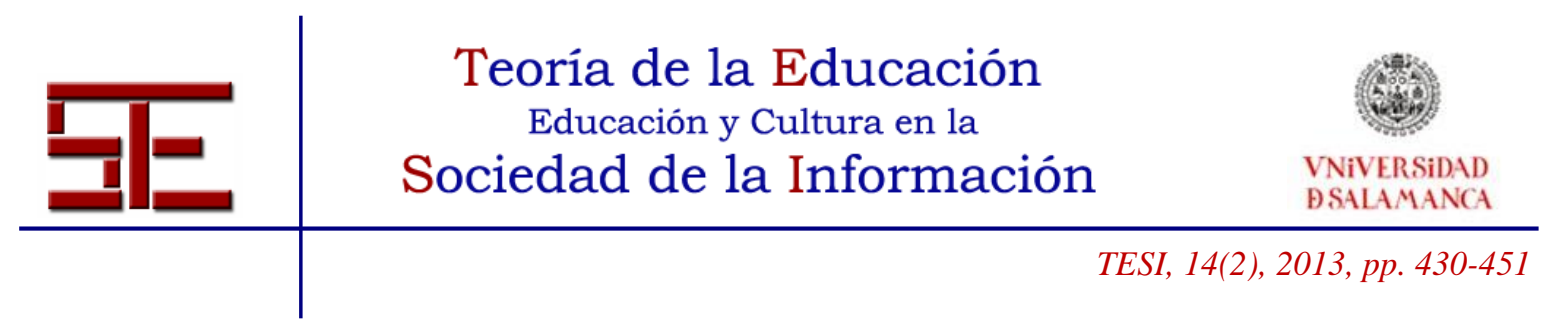

\section{A APRENDIZAGEM SOBRE INTERVALOS DE CONFIANÇA COM RECURSO AO SOFTWARE R}

Fecha de recepción: 08/01/2013; fecha de aceptación: 15/05/2013; fecha de publicación: 30/07/2013

Gariela Gonçalves

gmc@isep.ipp.pt

Instituto Superior de Engenharia do Porto

Luís Afonso

Ima@isep.ipp.pt

Instituto Superior de Engenharia do Porto

Marta Ferreira

mmp@isep.ipp.pt

Instituto Superior de Engenharia do Porto

Teresa Ferro

tmf@isep.ipp.pt

Instituto Superior de Engenharia do Porto

Maria M. Nascimento

mmns@utad.pt

Universidade de Trás-os-Montes e Alto Douro

\section{1.- INTRODUÇÃO}

A estatística é, nos dias de hoje, uma ferramenta indispensável para qualquer profissional que necessite de analisar informação para a tomada de decisão (Batanero, 2000). É importante decidir bem, mas a rapidez com que se toma a decisão também é um factor relevante. Mais informação pode beneficiar a qualidade da decisão, mas pode prejudicar a rapidez com que se toma. Para evitar isso, é necessário o recurso a meios tecnológicos para poder tomar decisões, envolvendo grandes volumes de informação. O ensino da estatística tem que evoluir também nesse sentido, tornando-se imperioso que os alunos utilizem meios tecnológicos durante a aprendizagem. A prática do ensino ao nível da Educação Estatística (literacia, pensamento e raciocínio estatístico) no ensino superior tem evidenciado dificuldades decorrentes da difícil compreensão desses conceitos por parte dos alunos.

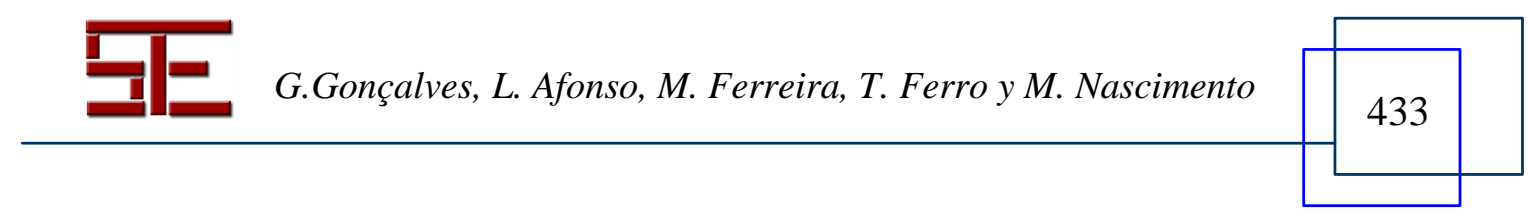




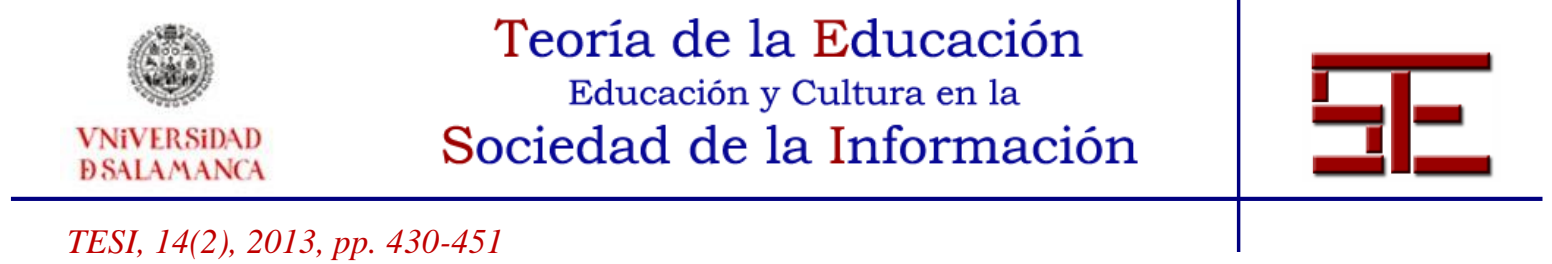

\section{1.- Intervalos de Confiança: antecedentes}

O tema dos intervalos de confiança tem um papel importante nas disciplinas de Estatística, tanto no ensino secundário (Ministério da Educação, 2001) como no ensino universitário. Trata-se de um procedimento geral da inferência estatística que se pode aplicar a diversos problemas tais como, o estudo de várias amostras, análise de correlação e regressão, etc.(Olivo,2008).

Clark (2004) considera que uma das vantagens da utilização dos intervalos de confiança tem haver com o facto de revelar ao investigador a margem de erro dos seus resultados e a amplitude da amostra observada.

Cumming e Finch (2001) salientam que os intervalos de confiança facilitam o pensamento meta-analítico que é um atributo essencial na análise dos dados estatísticos numa âmbito de uma investigação.

No entanto, segundo Shaughnessy (2007) trata-se de um conceito de difícil compreensão para os alunos. Apesar dos alunos construírem o intervalo de confiança utilizando fórmulas e realizando cálculos, é difícil para eles compreenderem o conceito uma vez que não lhe atribuem significado. Assim, é fundamental que os alunos aprendam conceitos estatísticos de uma forma que tenham significado para eles.

Associação Americana de Psicologia (APA) declarou acerca da importância dos intervalos de confiança (2001, citado em Olivo, 2008): Devido aos intervalos de confiança combinarem informação sobre a localização e precisão e muitas vezes poderem ser diretamente usados para inferir níveis de significância, eles são, em geral, a melhor estratégia a usar. $O$ uso dos intervalos de confiança é então fortemente recomendado (p.19).

Em geral, os intervalos de confiança traduzem uma das formas informativas de apresentar os resultados quantitativos de um estudo.

Em abordagens mais recentes, Henriques (2011) afirma que se deve "continuar a realizar estudos comparativos e longitudinais sobre a compreensão dos alunos acerca dos diferentes conceitos envolvidos na inferencia estatística e das causas das suas possiveis dificuldades" (n.p.).

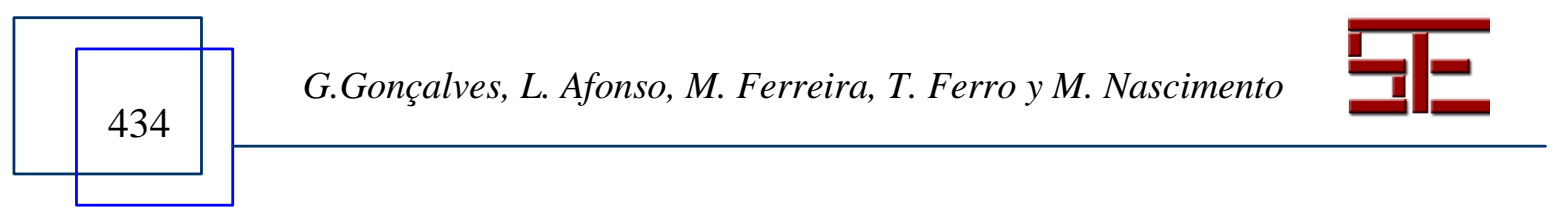




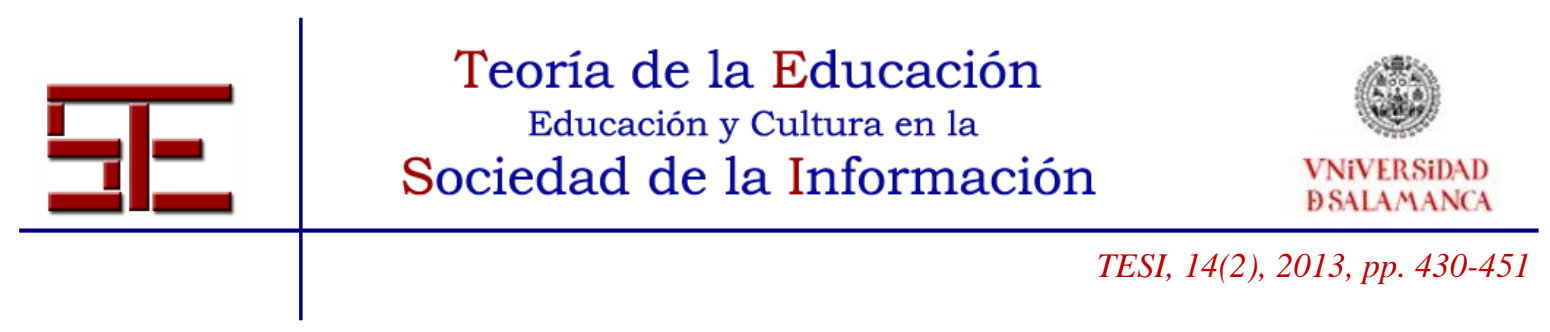

\section{2.- Problemas detetados}

Conceitos importantes em estudos estatísticos, incluindo intervalos de confiança, são referenciados como de difícil compreensão pelos alunos (Callaert, 2007). A prática no ensino desta temática por diversos docentes desta instituição confirma positivamente essa afirmação. Na realidade, em termos históricos, tem-se verificado que os alunos conseguem obter melhores resultados na teoria de probabilidades e suas extensões do que na estatística inferencial, especialmente na área das aplicações. A prática do ensino da estimação intervalar tem revelado os seguintes problemas: a) dificuldade na aprendizagem dos conceitos estatísticos relativos aos IC, designadamente na caracterização das varáveis aleatórias e no erro de estimação; b) fraca motivação; e c) défice de sinergias entre alunos e docentes.

\section{3.- Resposta aos problemas: Objetivos a atingir}

O objetivo deste projecto consistiu na implementação de um método para a melhoria da aprendizagem da estimação intervalar de parâmetros - intervalos de confiança. Para tal, divisou-se um novo método de ensino que passou pela utilização do software $\mathrm{R}$ de estatística, em conjunção com a realização de um trabalho prático, em equipa, procurando criar sinergias entre os alunos e os docentes e, desta forma, melhorar a aquisição dos conceitos.

Procurou-se também avaliar o impacto do uso desse software, como recurso pedagógico, introduzido nas aulas teórico-práticas, no âmbito da aprendizagem dos conceitos estatísticos relativos a intervalos de confiança.

Essa avaliação envolveu o novo método de ensino usando o software R. Além disso, avaliou-se o grau de motivação dos alunos nos intervalos de confiança neste ano letivo de $2011 / 2012$.

Nesse contexto, propusemo-nos fazer uma primeira abordagem à seguinte questão: $\mathrm{O}$ ensino deste tema com recurso ao software livre $\mathrm{R}$ promoverá uma melhor aprendizagem dos alunos nestes conceitos comparativamente com um ensino analítico?

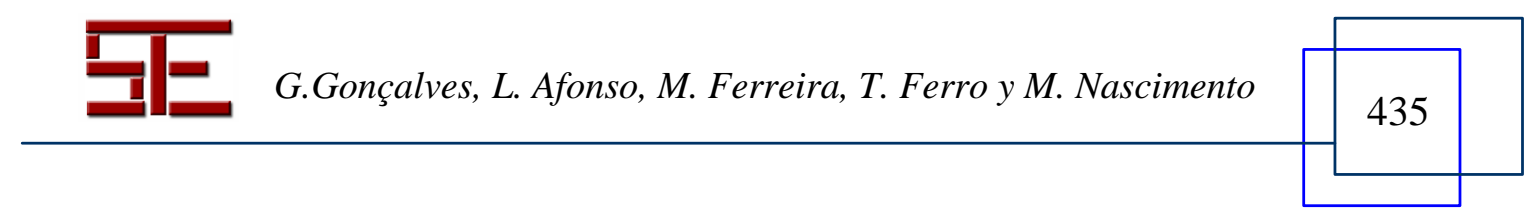




Teoria de la Educación
Educación y Cultura en la
$\begin{gathered}\text { VNIVERSADAD } \\ \text { BSALAMANCA }\end{gathered}$

\section{2.- METODOLOGIA}

Para atingir os objetivos propostos realizou-se uma experiência pedagógica na unidade curricular de Matemática Computacional, do primeiro ano da Licenciatura em Engenharia Informática do Instituto Superior de Engenharia do Porto, com cerca de 200 alunos inscritos no ano letivo de 2011/12. Na figura seguinte (Figura 1) apresenta-se o modelo usado para a implementação dos processos de avaliação e comparação de resultados obtidos em dois anos letivos consecutivos, respetivamente 2010/2011 e 2011/2012, com recurso ao método convencional de ensino assente unicamente na resolução analítica e ao novo método proposto cujo impacto se pretende avaliar.

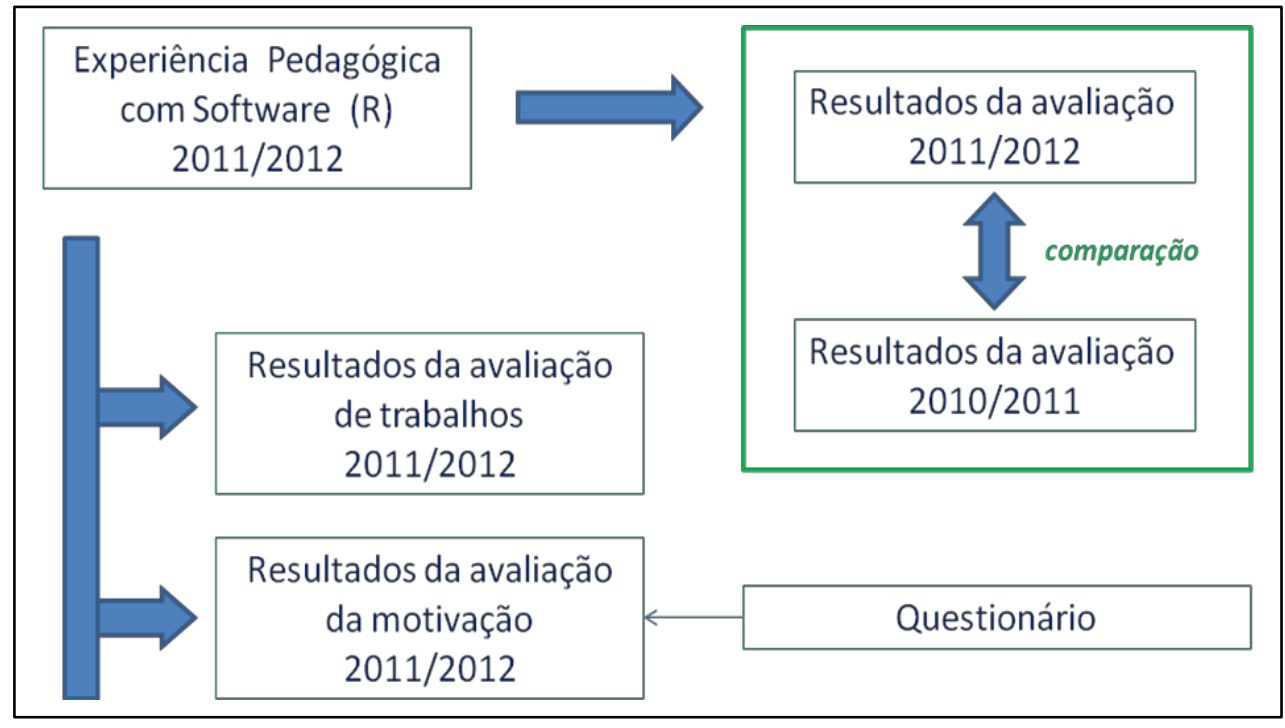

Figura 1. Metodologia adoptada

O conceito teórico de intervalo de confiança foi abordado em 2 aulas teóricas ( 2 h) e, posteriormente, aplicado em 3 aulas teórico-práticas $(4,5 \mathrm{~h})$, adotando um método de ensino que combinou o método de papel e lápis com o uso do software livre $\mathrm{R}$ (The $\mathrm{R}$ Project, http://www.r-project.org/).

$\mathrm{O}$ ambiente computacional $\mathrm{R}$ constitui um sistema livre especialmente vocacionado para o desenvolvimento de cálculos estatísticos, sendo largamente utilizado entre a

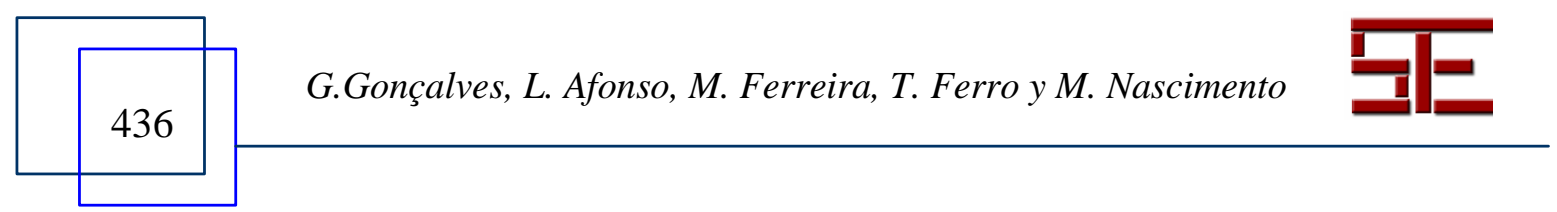




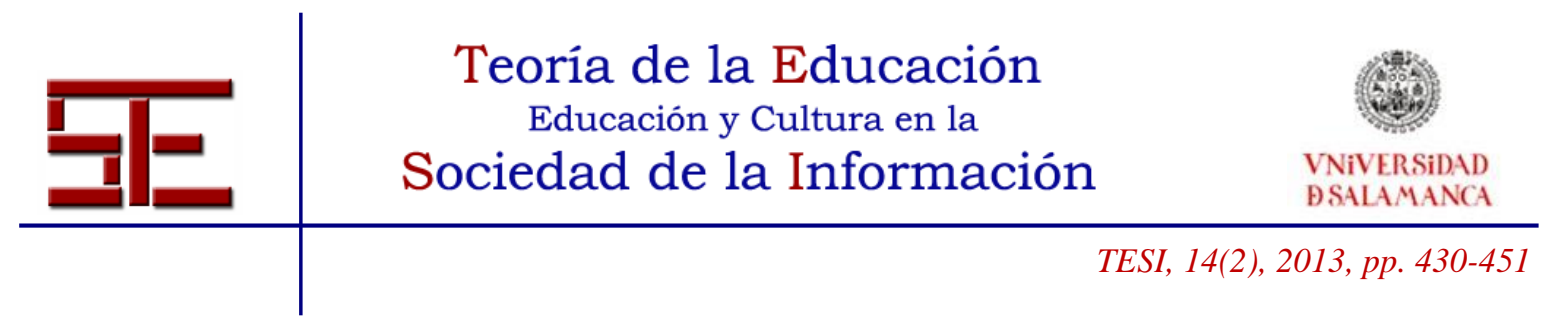

comunidade de utilizadores de estatística. Devido à sua especificidade e estrutura, este software permite:

- Uma rápida aprendizagem, especialmente para os alunos que já têm contacto com linguagens de programação;

- Uma forma rápida e económica na realização de cálculos estatísticos;

- O uso pelos alunos fora do ambiente escolar (por não necessitar de licença).

No sentido de estudar a adesão dos alunos ao software e a sua interligação com conceitos teóricos foi proposto um trabalho, a realizar pelos alunos, que consistia na resolução de um conjunto de problemas, que deveriam ser resolvidos tal como foi feito nas aulas teórico-práticas, respetivamente, de forma tradicional (papel e lápis) e usando o software $\mathrm{R}$, tendo ainda os alunos de analisar, comparar e comentar os resultados obtidos.

A avaliação do impacto da utilização do Software R como recurso de aprendizagem dos alunos do conceito de intervalo de confiança foi realizada sob duas perspetivas, que passaremos a analisar.

\section{1.- Avaliação pedagógica}

Foi proposto aos alunos a realização de um trabalho prático, com dados reais, sobre o tema intervalos de confiança composto por duas questões abordando os parâmetros média e proporção. Nestas questões foram avaliadas a resolução analítica (papel e lápis) e a resolução computacional com recurso ao software R. A tarefa apresenta-se na Figura 2, que inclui as indicações dadas aos alunos (ver questão 2) para a elaboração do relatório.

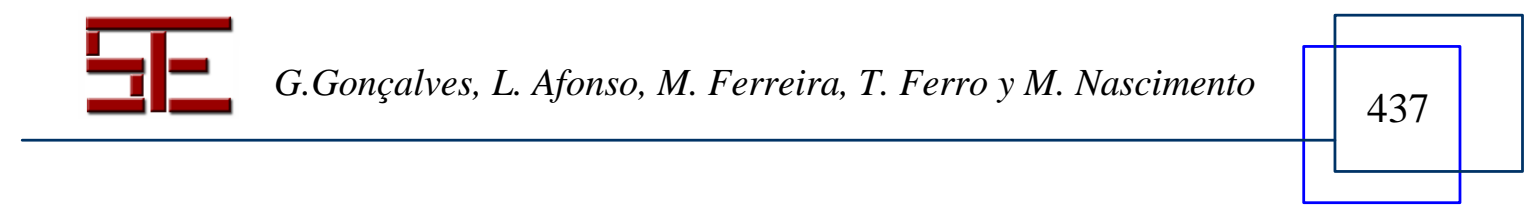




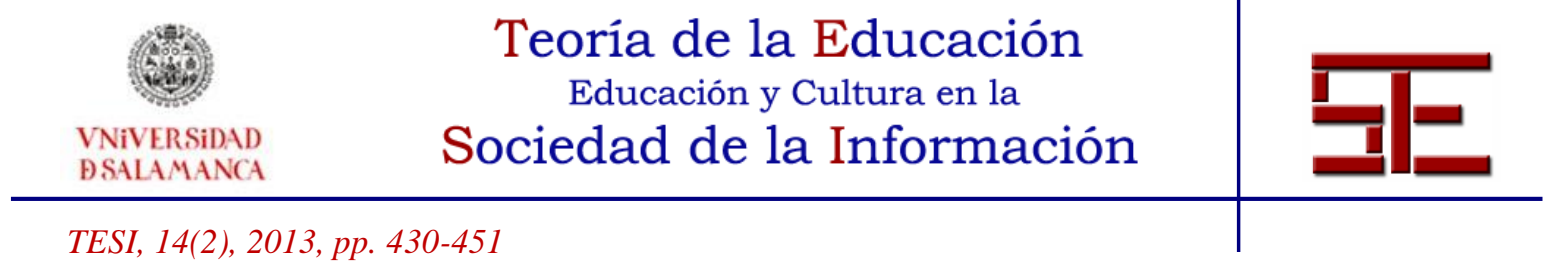

\section{Trabalho de MATCP}

Numa empresa de informática pretende-se avaliar a eficácia de dois programas de formação. Um grupo de 60 alunos, recém-licenciados, é aleatoriamente indicado para os dois programas, de modo que existam 30 sujeitos em cada programa. No final do período de formação, cuja duração foi um mês, é aplicado um exame aos 60 alunos. Os resultados, numa escala de 0 a 20 pontos, são apresentados na tabela seguinte.

\begin{tabular}{|l|l|l|l|l|l|l|l|l|l|l|l|}
\hline \multicolumn{9}{|c|}{ Programa A } & \multicolumn{7}{c|}{ Programa B } \\
\hline 66 & 72 & 74 & 51 & 82 & 91 & 61 & 63 & 60 & 61 & 57 & 80 \\
\hline 59 & 75 & 62 & 73 & 74 & 56 & 76 & 60 & 84 & 81 & 58 & 51 \\
\hline 97 & 64 & 87 & 78 & 78 & 67 & 55 & 65 & 70 & 69 & 71 & 71 \\
\hline 63 & 71 & 65 & 56 & 74 & 78 & 80 & 91 & 54 & 71 & 62 & 57 \\
\hline 88 & 65 & 77 & 63 & 79 & 68 & 53 & 67 & 61 & 72 & 50 & 55 \\
\hline
\end{tabular}

Admitindo que a distribuição das pontuações é normal:

1 .

a) Construa um IC a 95\% para a pontuação média de um aluno que se submeta ao programa $A$.

b) Calcule um IC a 95\% para a \% de alunos que obtém mais de 70 pontos.

2. Cada grupo deverá elaborar um relatório em computador que não ultrapasse 5 folhas onde conste

a) Identificação dos elementos: nome, número e turma

b) Enunciado

c) Respostas às alíneas propostas:

i) Na forma analítica de acordo com as aulas TP.

ii) Na forma computacional com o recurso ao $\mathrm{R}$.

Figura 2: Enunciado da tarefa

Pretendeu-se com a realização do trabalho em grupo promover uma melhor aprendizagem dos intervalos de confiança. Num total de 193 alunos, organizaram-se 79 grupos (com 2 ou 3 alunos por grupo) e 5 alunos trabalharam individualmente (por impossibilidade de trabalharem em grupo). Este trabalho tinha um peso de $10 \%$ na nota final da avaliação. Além disso, os alunos puderam tirar dúvidas com os seus professores nas horas tutoriais.

Para comparar os resultados obtidos analisaram-se as questões de exame do ano letivo 2010/2011 que envolviam intervalos de confiança (nos 186 testes realizados) e a mesma

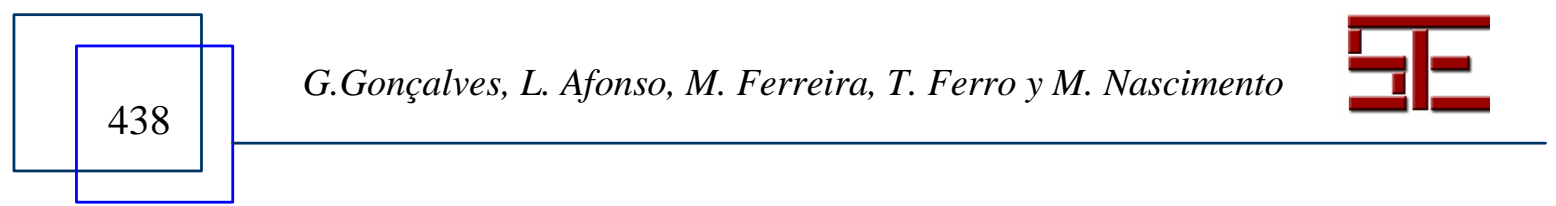




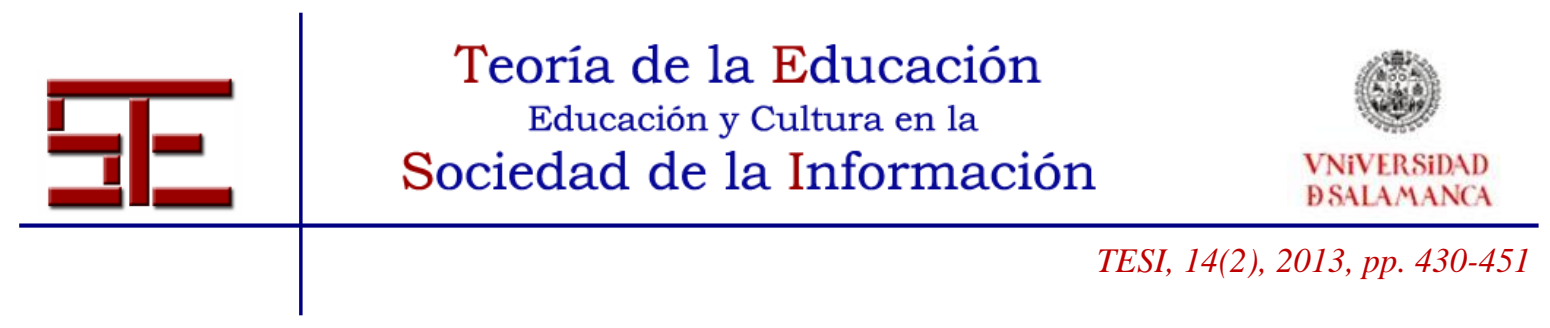

questão nas provas de exame do ano letivo seguinte de 2011/2012 (nos 188 testes realizados). No ano letivo 2010/2011 o ensino foi ministrado pelo mesmo grupo de docentes com a mesma tipologia de aulas, mas usando apenas o método tradicional de papel e lápis.

\section{2.- Motivação}

Para avaliar esta componente foi realizado um questionário (anónimo e facultativo) com o objetivo de recolher a opinião dos alunos sob o trabalho realizado, contemplando: a funcionalidade do R; e o incentivo ao estudo e aprendizagem dos conceitos. Este questionário é apresentado no anexo A. O questionário foi colocado no "Google docs", simultâneamente foi enviado um email aos alunos, no sentido de os informar da disponibilidade do mesmo e de que teriam 15 dias para responder, e foi ainda esclarecido o modo de preenchimento na própria plataforma. O questionário foi aplicado no final do semestre e antes do exame, para que os resultados deste não influenciassem as respostas dos alunos.

\section{3.- ANÁLISE DE RESULTADOS}

Nesta secção procede-se a uma primeira análise da viabilidade e interesse da implementação desta prática pedagógica, incluindo o recurso ao software R.

\section{1.- Análise Comparativa}

Os resultados obtidos nos anos letivos 2010/2011 e 2011/2012 (ano em que se introduziu o software R) estão expressos na Tabela 1. Destacamos, destes resultados, que o número de respostas excelentes duplicou a sua proporção com a introdução da nova metodologia. Também a proporção de respostas que cumpriram mais de metade dos objectivos pretendidos nas questões sobre intervalos de confiança (nomeadamente nos aspetos que envolvem a definição de variáveis aleatórias, a compreensão e cálculo do erro de estimação, a relação entre o erro de estimação e o intervalo de confiança e a interpretação do significado do intervalo de confiança no contexto do problema em estudo) teve um crescimento substancial passando de $43 \%$ para $62,2 \%$. No sentido inverso, a proporção de respostas incorrectas decresceu para cerca de metade.

\begin{tabular}{|l|c|c|c|} 
& Questões & $N^{\circ}$ respostas & \% de respostas \\
Ano letivo 2010/11 & $\begin{array}{c}\text { Respostas de } \\
\text { excelência }\end{array}$ & 11 & 5,9 \\
\cline { 3 - 4 }
\end{tabular}

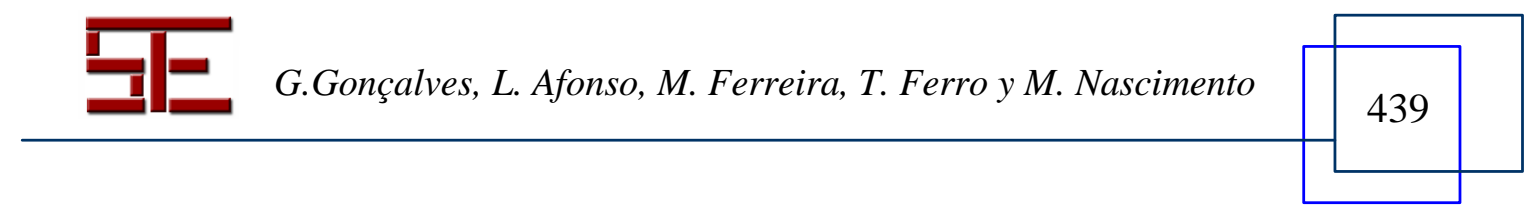




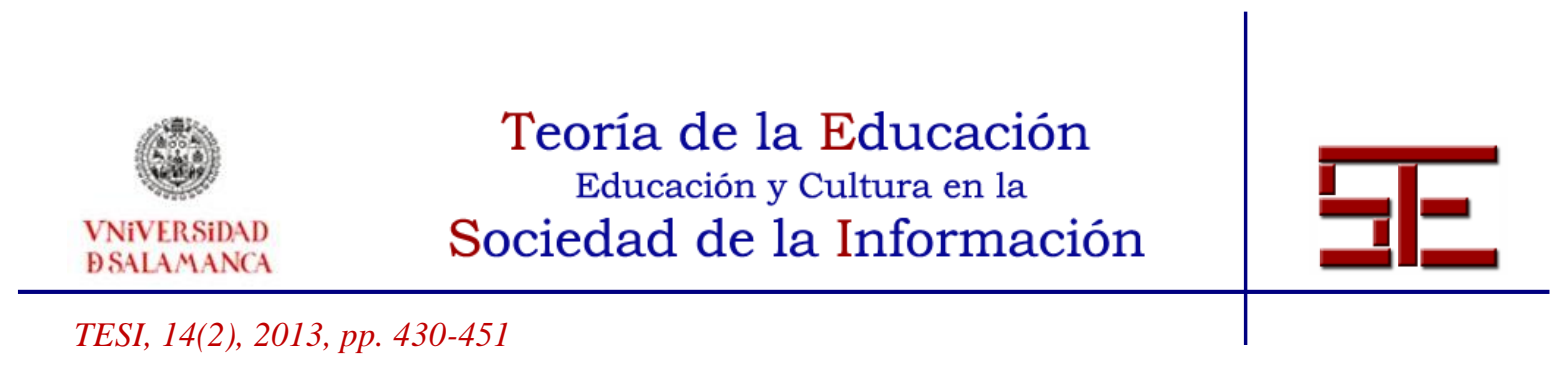

\begin{tabular}{|c|c|c|c|}
\hline & Semicorretas & 69 & 37,1 \\
\hline & Incorretas & 72 & 38,7 \\
\hline & Sem resposta & 34 & 18,3 \\
\hline & Total & 186 & 100 \\
\hline \multirow{5}{*}{ Ano letivo $2011 / 12$} & $\begin{array}{c}\text { Respostas de } \\
\text { Excelência }\end{array}$ & 23 & 12,2 \\
\hline & Semi-corretas & 94 & 50,0 \\
\hline & Incorretas & 36 & 19,1 \\
\hline & Sem resposta & 35 & 18,6 \\
\hline & Total & 188 & 100 \\
\hline
\end{tabular}

Tabela 1. Resultados comparativos de dois anos letivos.

Na Figura 3 apresenta-se a distribuição dos diferentes tipos de respostas dos alunos nos dois anos letivos consecutivos, no último dos quais foi implementado o novo método.

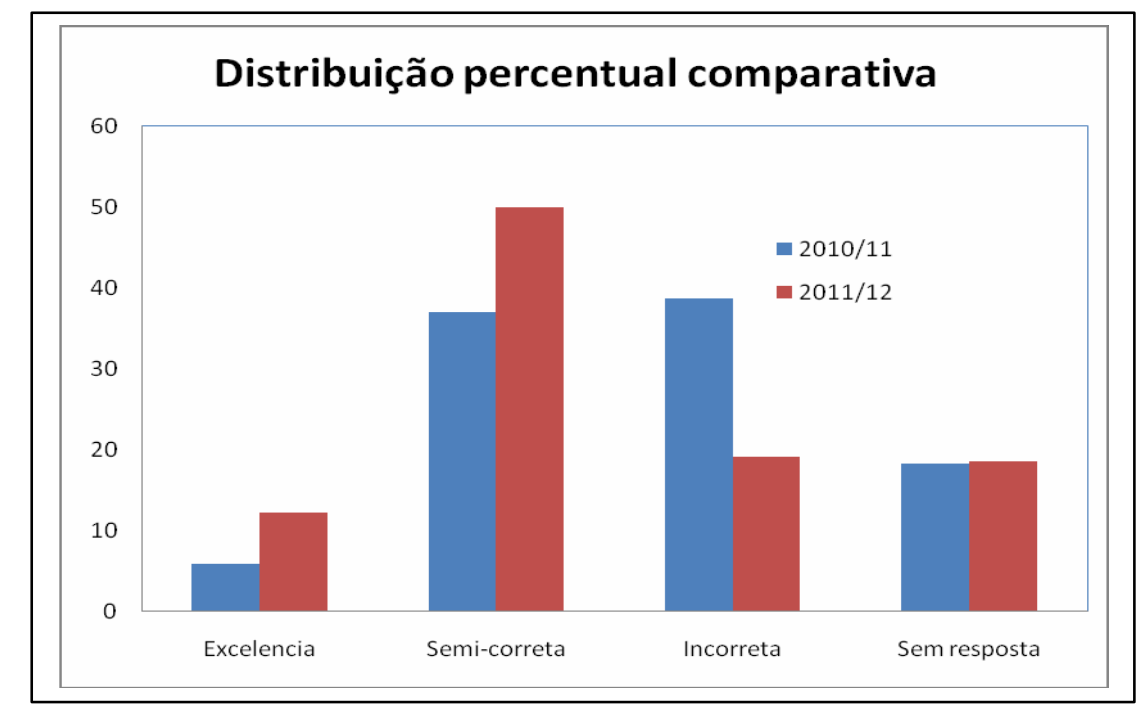

Figura 3. Distribuição percentual comparativa relativamente ao tipo de resposta

Para averiguar se o aumento na proporção de alunos que cumpriram mais de metade dos objetivos, pela introdução da nova estratégia de ensino, é confirmada em termos de significância estatística e pode ser extrapolada para a população em estudo, levamos a

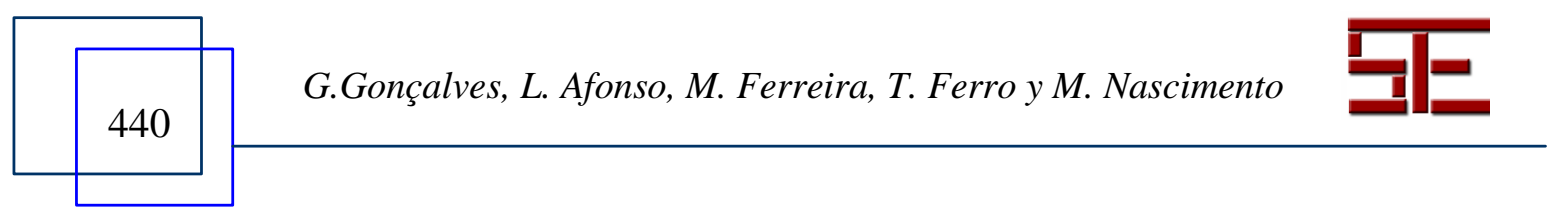




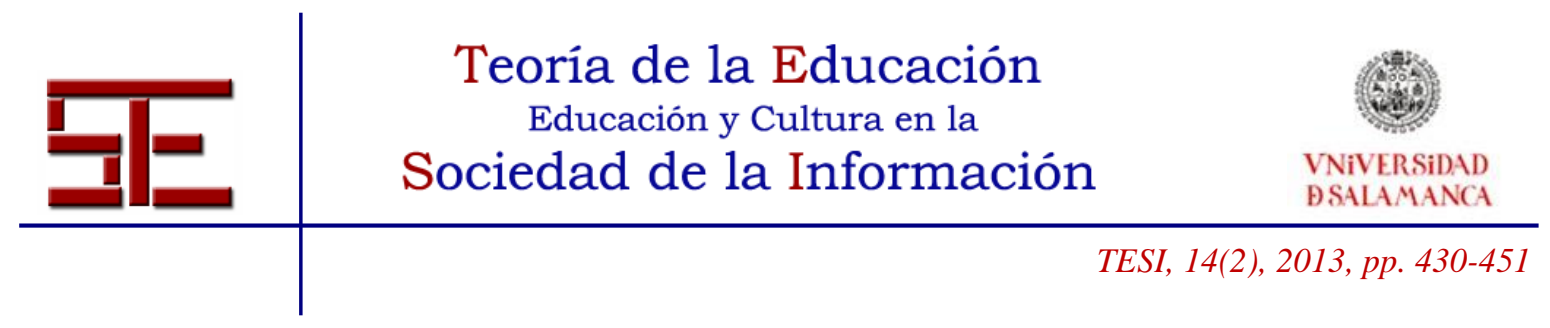

cabo um teste da diferença de proporções. Os resultados do teste permitem rejeitar a hipótese nula de que não existe diferença (valor de prova $\mathrm{p}=0.0001$, que indica um risco de erro do tipo I muito baixo), sendo possível concluir que os resultados são estatisticamente significativos e podem ser considerados para a população a que o estudo se refere.

Relativamente às respostas de excelência, que revelam cuidado com a escrita e justificações teóricas, efetuamos o mesmo teste e o resultado do mesmo (valor de prova $\mathrm{p}=0.0001$ ) permite retirar conclusões semelhantes, isto é, os resultados amostrais são estatisticamente significativos.

Todavia, verificamos que a percentagem de alunos que não responderam às questões de estimação intervalar não sofreu variação significativa. Atribuímos este fenómeno como sendo característico da existência de uma percentagem de alunos que antecipadamente coloca de parte a matéria de inferência. Em termos históricos, tem-se verificado que esta percentagem se tem mantido constante nos últimos anos, sendo o seu valor de cerca de $20 \%$.

\section{2.- Análise dos trabalhos}

Dos grupos de alunos que participaram nesta experiência de 2011/2012 sobre intervalos de confiança, $90 \%$ obtiveram notas positivas (9,5 a 20 valores). Dos alunos que tiveram notas positivas, $76 \%$ cumpriram mais de $60 \%$ dos objetivos pretendidos com este traba lho nos aspetos de resolução das questões (tal como foram apresentados nas questões de exame em 3.1). Dos alunos que obtiveram notas negativas, pode considerar-se que $49 \%$ cumpriram parcialmente esses aspetos, verificando-se mesmo assim que, como primeira análise desta proposta de trabalho para os intervalos de confiança, os alunos deste ano letivo já revelaram ter aprendido os conceitos deste conteúdo.

Em seguida, na Figura 4, apresentam-se, a título de exemplo, uma resolução retirada dos relatórios sobre a utilização do $\mathrm{R}$ e no Anexo B a correspondente resolução analítica. Verificamos assim que existem evidências de que os alunos, para além de terem aprendido a usar o R, conseguiram usá-lo para confirmar as suas resoluções com papel e lápis.

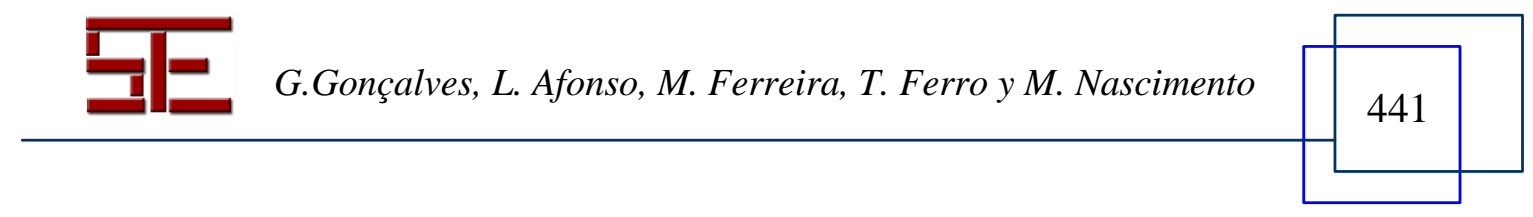



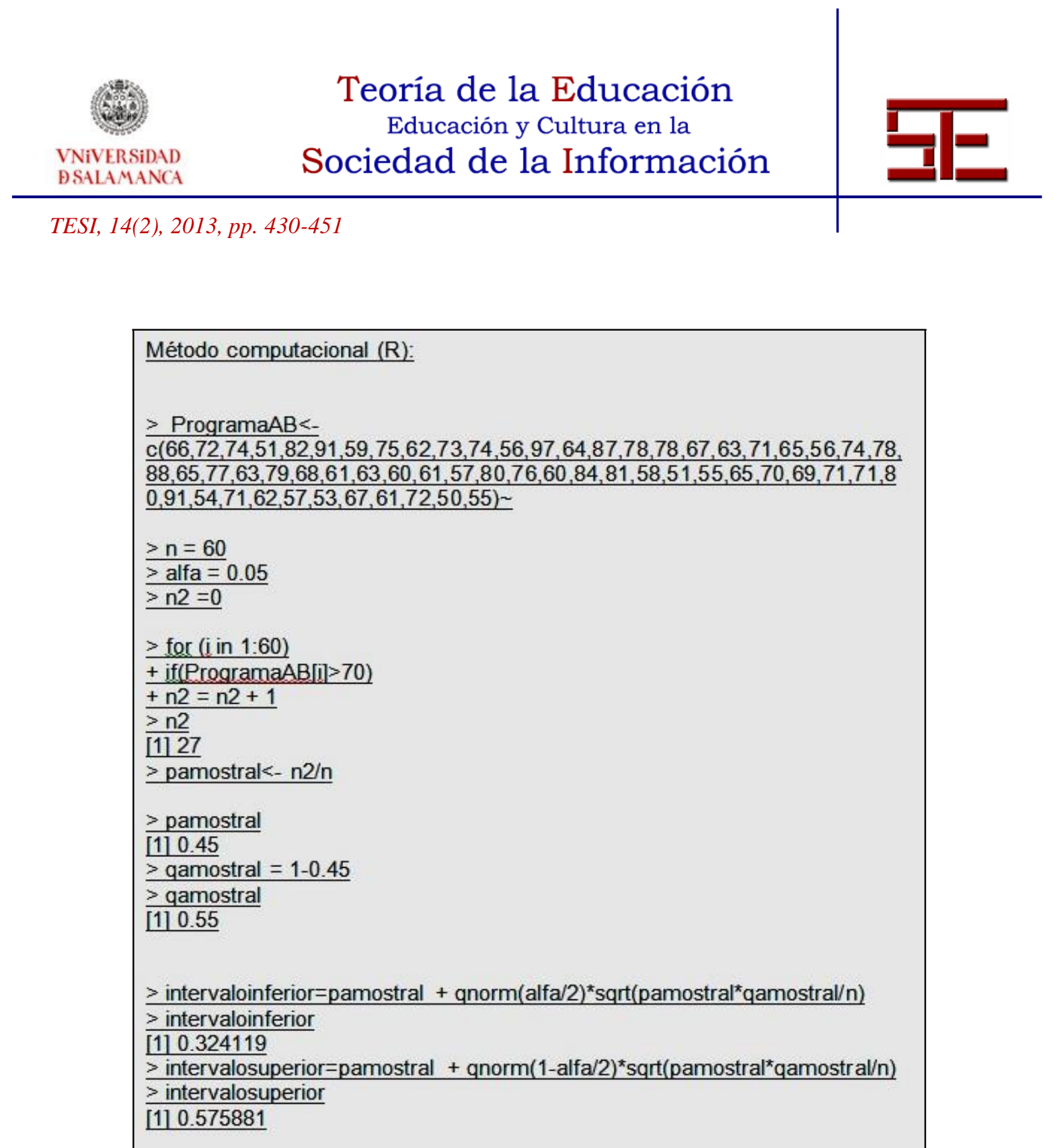

Figura 4. Exemplo de resolução do problema proposto utilizando o R

\section{3.- Análise dos questionários}

Os resultados globais (Figura 5) dos questionários anónimos e facultativos, realizados por 106 dos 193 alunos de 2011/2012, revelam que 64\% dos alunos recomenda o R como recurso pedagógico, notando-se que apenas $25 \%$ não tem opinião formada. Relativamente à assimilação dos conceitos apenas $19 \%$ dos alunos considera que não houve melhorias na aprendizagem dos conceitos e apenas $9 \%$ dos alunos discordam que a utilização do $\mathrm{R}$ não é intuitiva.

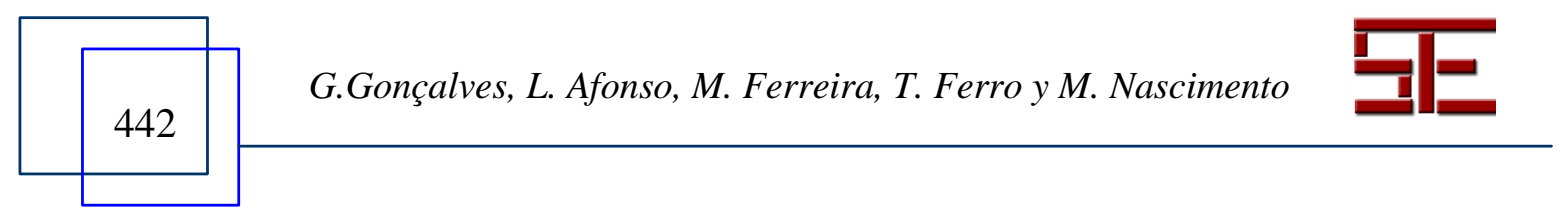



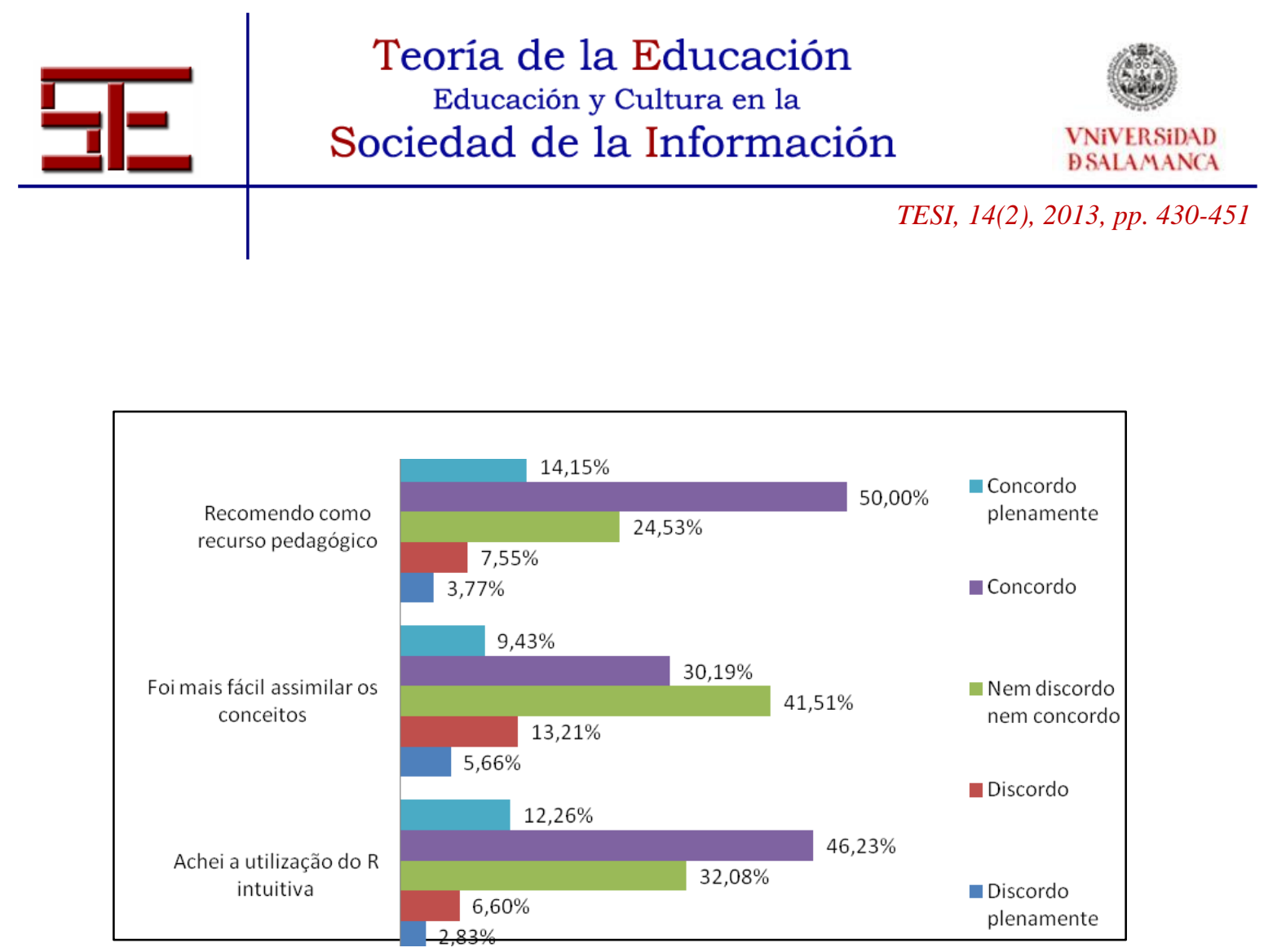

Figura 5. Gráfico das respostas dos alunos sobre a aprendizagem com o R

A maioria dos alunos que achou a utilização do $\mathrm{R}$ intuitiva gostaria de usar este software no futuro. De facto, na Tabela 2, observa-se que dos 62 alunos que concordam que o R é intuitivo, 45 também consideram que gostariam de o usar no futuro (cerca de $73 \%$ ). Situação análoga se verifica para os alunos que discordam de ambos os itens, agora uma minoria de cerca $18 \%$.

\begin{tabular}{|c|c|c|c|c|c|c|c|}
\hline & & \multicolumn{5}{|c|}{$\begin{array}{l}\text { Gostava de voltar a utilizar o } \mathrm{R} \\
\text { noutra disciplina da mesma área }\end{array}$} & \multirow[t]{2}{*}{ Total } \\
\hline & & 1 & 2 & 3 & 4 & 5 & \\
\hline \multirow{5}{*}{$\begin{array}{l}\text { Achei a utilização do } \mathrm{R} \\
\text { intuitiva }\end{array}$} & 1 & 2 & 1 & 0 & 0 & 0 & \multirow[t]{2}{*}{10} \\
\hline & 2 & 3 & 2 & 1 & 1 & 0 & \\
\hline & 3 & 1 & 5 & 19 & 7 & 2 & 34 \\
\hline & 4 & 1 & 2 & 14 & 27 & 5 & \multirow[t]{2}{*}{62} \\
\hline & 5 & 0 & 0 & 0 & 10 & 3 & \\
\hline \multicolumn{2}{|l|}{ Total } & \multicolumn{2}{|c|}{17} & 34 & \multicolumn{2}{|c|}{55} & 106 \\
\hline \multicolumn{8}{|c|}{$\begin{array}{l}1 \text { - Discordo Plenamente; } 2 \text { - Discordo; } 3 \text { - Nem discordo nem concordo; } 4 \text { - } \\
\text { Concordo; } 5 \text { - Concordo plenamente. }\end{array}$} \\
\hline
\end{tabular}

ש.Gonçalves, L. Afonso, M. Ferreira, T. Ferro y M. Nascimento 


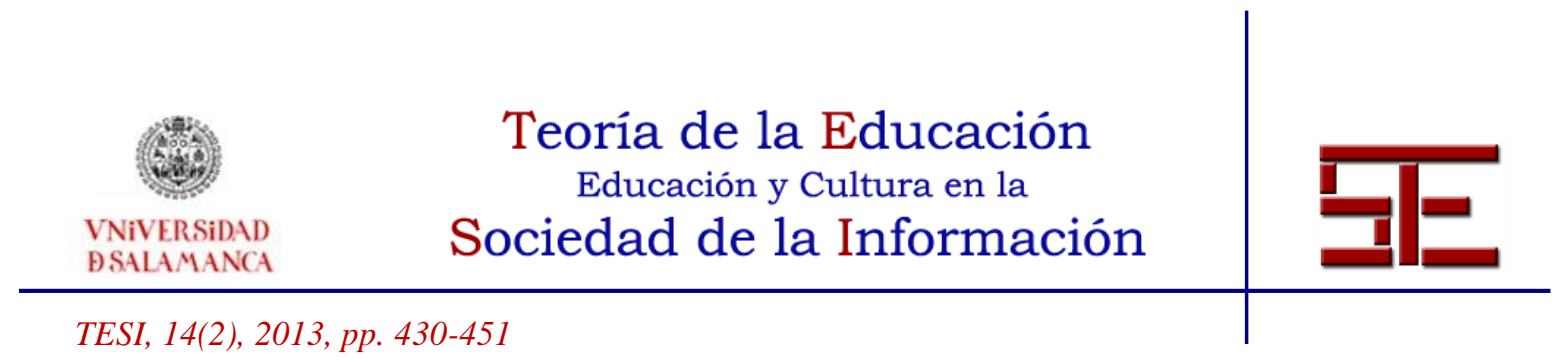

Tabela 2. Respostas utilização intuitiva versus voltar a utilizar o $\mathrm{R}$ noutra disciplina da mesma área

Relativamente à relação entre a utilização intuitiva e a contribuição para a melhoria da aprendizagem dos conceitos (Tabela 3), verificou-se que a maioria dos alunos achou a utilização do $\mathrm{R}$ intuitiva e que promoveu a melhoria da aquisição dos conceitos.

\begin{tabular}{|c|c|c|c|c|c|c|c|}
\hline & & \multicolumn{5}{|c|}{$\begin{array}{l}\text { Foi mais fácil assimilar os } \\
\text { conceitos envolvidos na disciplina } \\
\text { com a utilização do } \mathrm{R}\end{array}$} & \multirow[t]{2}{*}{ Total } \\
\hline & & 1 & 2 & 3 & 4 & 5 & \\
\hline \multirow{5}{*}{$\begin{array}{l}\text { Achei a utilização do } \\
\mathrm{R} \text { intuitiva }\end{array}$} & 1 & 3 & 0 & 0 & 0 & 0 & \multirow{2}{*}{10} \\
\hline & 2 & 3 & 2 & 2 & 0 & 0 & \\
\hline & 3 & 0 & 6 & 22 & 6 & 0 & 34 \\
\hline & 4 & 0 & 6 & 17 & 21 & 5 & \multirow{2}{*}{61} \\
\hline & 5 & 0 & 0 & 3 & 5 & 4 & \\
\hline \multicolumn{2}{|l|}{ Total } & \multicolumn{2}{|c|}{20} & 44 & \multicolumn{2}{|c|}{41} & 105 \\
\hline
\end{tabular}

Tabela 3. Respostas utilização intuitiva versus melhoria da assimilação dos conceitos

Foram também analisadas as opiniões dos alunos acerca das vantagens e desvantagens da utilização do software na sala de aula. Os resultados desta análise, expressos na Figura 6, permitem constatar que a principal desvantagem, encontrada pelos alunos, consistiu no investimento inicial de tempo necessário para a aprendizagem do R. No que concerne às vantagens na utilização do software, os alunos enfatizam a simplificação do processo de aprendizagem, o estímulo ao estudo e o trabalho em equipa. 

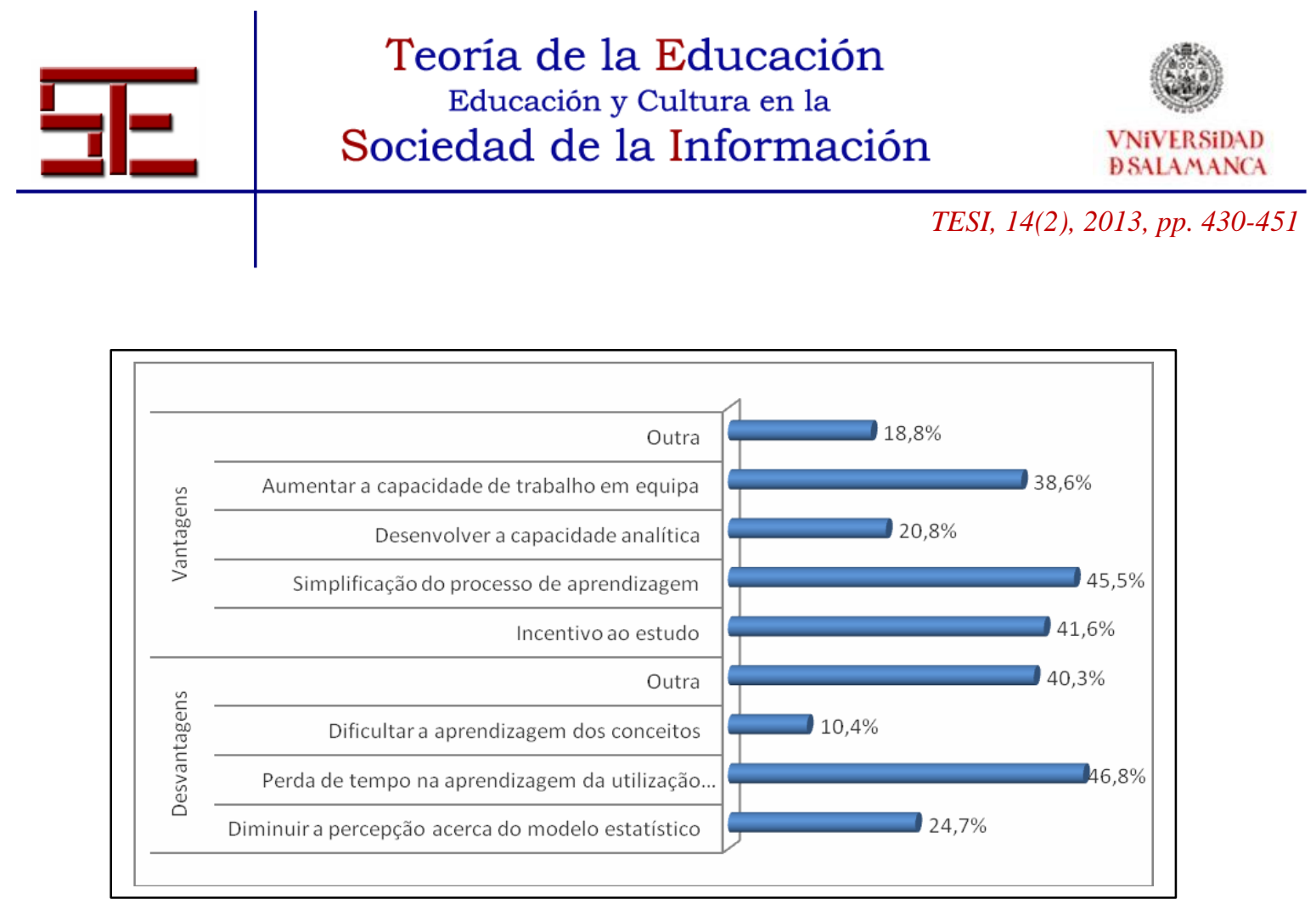

Figura 6. Vantagens e desvantagens do uso do software R

\section{4.- CONCLUSÕES}

A análise dos resultados das questões dos exames realizadas pelos alunos mostrou que foi maior a percentagem de alunos com respostas corretas em 2011/12, ano letivo em que foi combinado o uso do papel e lápis com o software R. Esta constatação sugere que, de um modo geral, neste ano letivo a utilização do sofware $\mathrm{R}$ permitiu que os alunos compreendessem melhor o conceito de intervalo de confiança. Apesar de alguns autores terem verificado nos seus estudos que os alunos revelam dificuldades conceptuais, procedimentais e interpretativas em relação a este conceito (Callaert, 2007; Olivo \& Batanero, 2007), os resultados sugerem que estas dificuldades podem ser progressivamente superadas com o recurso a ferramentas computacionais.

Face aos resultados comparativos obtidos nas questões de exames e aos resultados obtidos na realização do trabalho prático, é nossa opinião que o uso do software R motivou os alunos para uma melhor aprendizagem de conceitos de intervalos de confiança. Possivelmente, o facto de estes alunos serem de Engenharia Informática tornou-os mais sensíveis à aprendizagem usando softwares, nomeadamente o R.

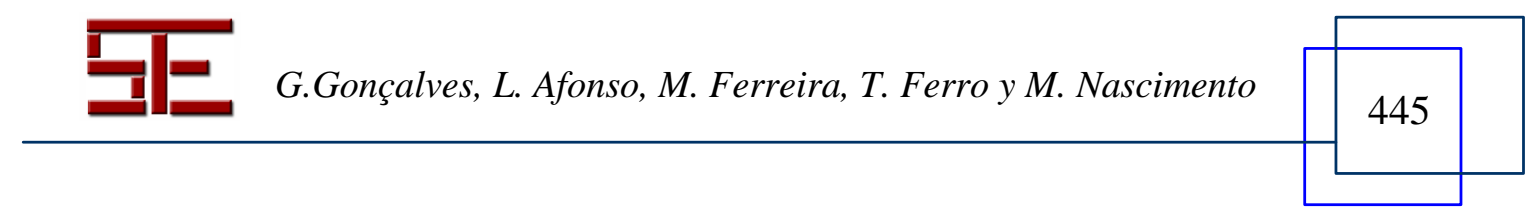




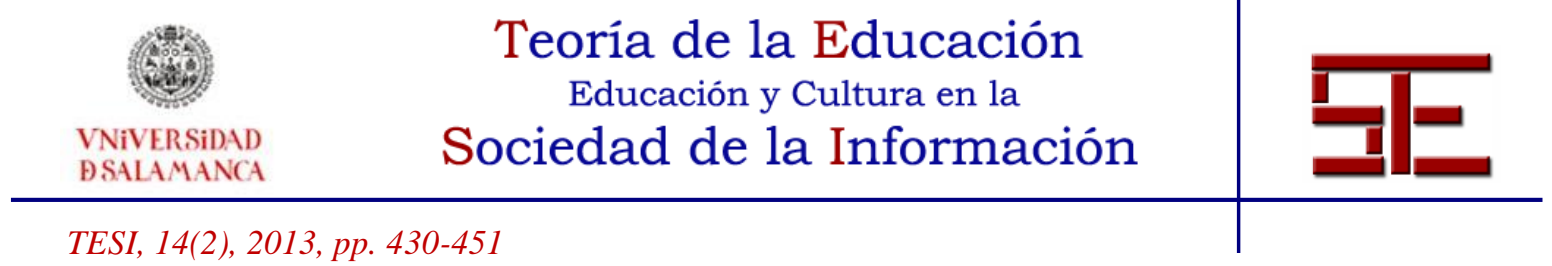

Por um lado, advogando que "É no interior do processo educativo que podemos encontrar algumas das respostas para as questões que surgem a partir do uso do computador e que remetem à transformação da prática do educador" (Valente, 1999); e, por outro lado, considerando a importância do intervalo de confiança e a necessidade do seu uso na investigação (Olivo \& Batanero, 2007), recomendamos que em futuras investigações se explore mais a utilização de softwares estatísticos para a aprendizagem de conceitos relacionados com a inferência estatística. Todavia, os resultados obtidos confirmam que a percentagem de alunos que não responderam às questões de estimação intervalar se tem mantido constante. Um futuro desafio será perceber quais as causas que estão associadas e procurar medidas que motivem esses alunos para o estudo da estimação intervalar.

\section{5.- BIBLIOGRAFIA}

American Psychological Association (2001). Publicational manual of the American Psychology Association, 5. Washing: DC.

Batanero, C. (2000). Controversies around significance tests. Journal of Mathematics Thaching and Learning, 2(1\&2), 75-98.

Callaert H. (2007). Understanding confidence intervals. Proceedings of CERME 5Working Group 5: Stochastic Thinking.

On line: http://www.erme.unito.it/CERME5b/WG5.pdf\#page $=79$

Clark, L. (2004). Los valores p y los intervalos de confianza. En qué confiar? Revista Panamericana de Salud Pública, 15 (5), 295-296.

Henriques, A. (2011). Dificuldades na Compreensão de Intervalos de Confiança: um estudo com alunos universitários. Actas do XXII SIEM, Lisboa, Portugal.

Cumming, G. \& Finch, S. (2001). A primer understanding, use, and calculation of confidence intervals that are based on central and non-central distributions. Educational and Psychological Measurement, 61, 530-572.

Olivo E. (2008). Significado de los intervalos de confianza para los estudantes de ingeniería en México. Tese de doutoramento, Universidad de Granada, Granada, Espanha.

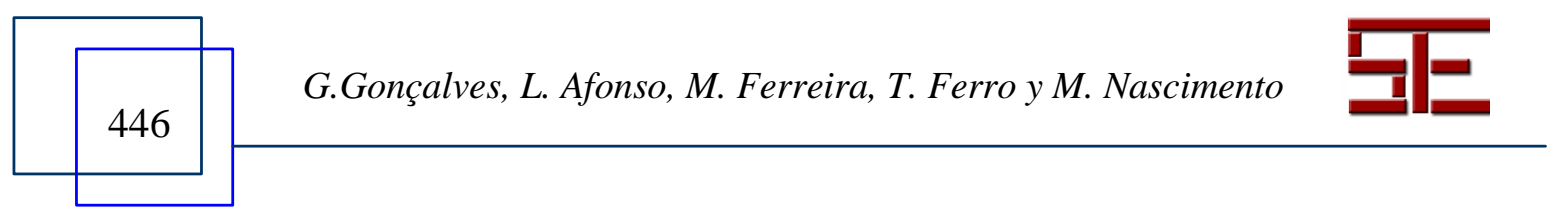




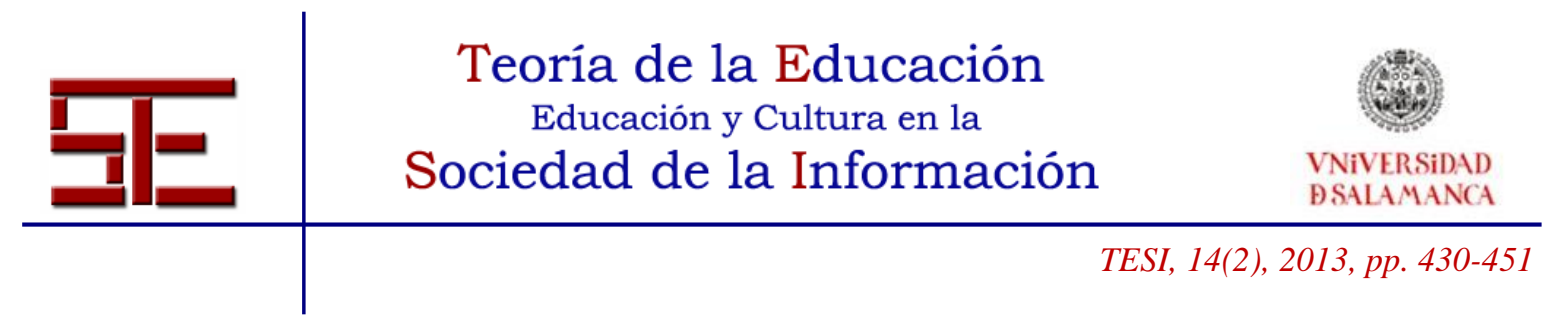

Olivo E. \& Batanero, C. (2007). Un estudio exploratório de dificuldades de comprensión del intervalo de confianza. Unión, 12, 37-51.

Shaughnessy, J. M. (2007). Research on statistics learning and reasoning. In F. K. Lester, Jr. (Ed), Second handbook of research on mathematics teaching and learning (pp.9571009). Greenwich, CT: Information Age Publishing and National Council of Teachers of Mathematics.

Valente, A. (1999). Mudanças na sociedade, mudanças na educação: o fazer e o compreender. O computador na sociedade do conhecimento. UNICAMP-NIED, 156, 2937.

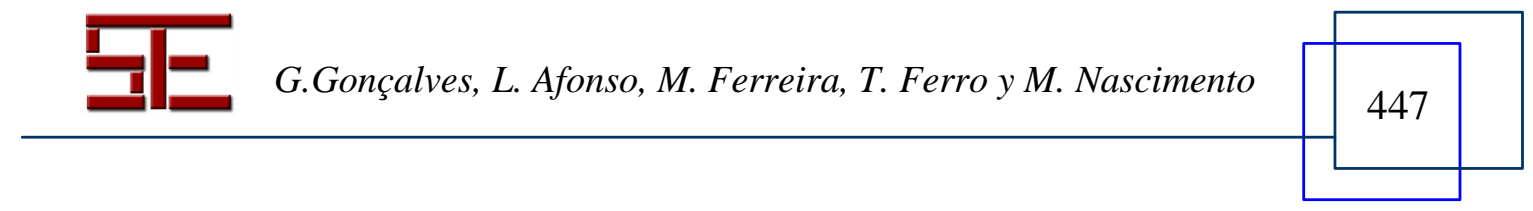




Teoría de la Educación
Educación y Cultura en la
$\begin{gathered}\text { VNIVERSIDAD } \\ \text { DSALAMANCA }\end{gathered}$

\section{6.- ANEXO A - Questionário}

\section{Inquérito sobre a utilização do $\mathrm{R}$ na disciplina de MATCP}

Este inquérito tem como objetivo avaliar o impacto da introdução do $\mathrm{R}$ como ferramenta pedagógica. As respostas são confidenciais e servem apenas para fins estatísticos.

E a primeira vez que frequento a disciplina.
- Sim
- Não

E a primeira vez que utilizo um software de matemática/estatística.
- Sim
- Não

E a primeira vez que utilizo o $R$.

- $\operatorname{Sim}$

- Não

Achei a utilização do $\mathrm{R}$ intuitiva.

- Discordo plenamente

- Discordo

- Nem discordo nem concordo

- Concordo

- Concordo plenamente

Gostava de voltar a utilizar o $\mathrm{R}$ noutra disciplina da mesma área.

- Discordo plenamente

- Discordo

- Nem discordo nem concordo

- Concordo

- Concordo plenamente

Gostava de utilizar um software de matemática/ estatística noutras disciplinas da mesma área.

- Discordo plenamente

- Discordo

- Nem discordo nem concordo

- Concordo

- Concordo plenamente

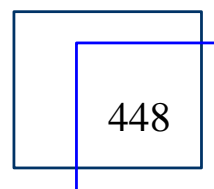

G.Gonçalves, L. Afonso, M. Ferreira, T. Ferro y M. Nascimento 


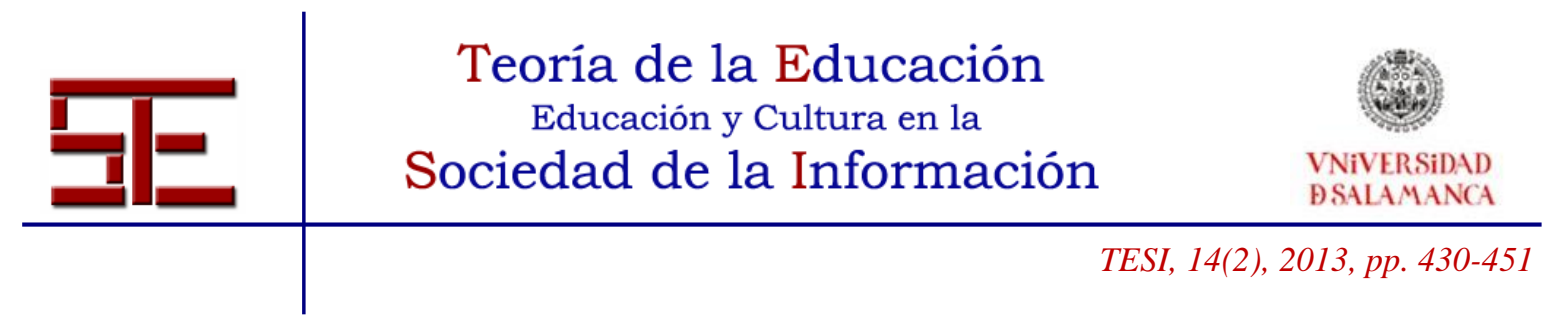

Foi mais fácil assimilar os conceitos envolvidos na disciplina com a utilização do $\mathrm{R}$.

- Discordo

- Nem discordo nem concordo

- Concordo

- Concordo plenamente

Recomendo a utilização de software de matemáticalestatística como recurso pedagógico.

- Discordo plenamente

- Discordo

- Nem discordo nem concordo

- Concordo

- Concordo plenamente

Recomendo a utilização $\mathrm{R}$ como recurso pedagógico.

- Discordo plenamente

- Discordo

- Nem discordo nem concordo

- Concordo

- Concordo plenamente

Que vantagens,encontrou na utilização do $R$, relativamente à disciplina de MATCP (escolha 2 no máximo)

- Incentivo ao estudo

- Simplificação do processo de aprendizagem

- Aumentar a capacidade de trabalho em equipa

- Desenvolver a capacidade analítica

- Outra

Que desvantagens encontrou na utilização do $\mathrm{R}$, relativamente à disciplina de MATCP (escolha 2 no máximo)

- Diminuir a perceção acerca do modelo estatístico

- Dificultar a aprendizagem dos conceitos

- Perda de tempo na aprendizagem da utilização do software

- Outra

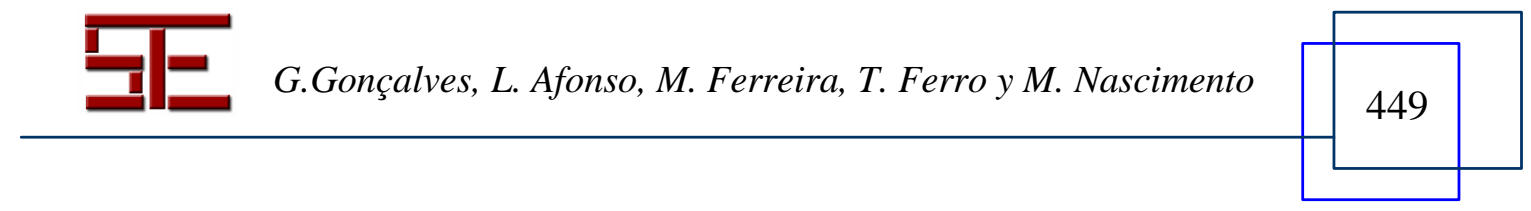




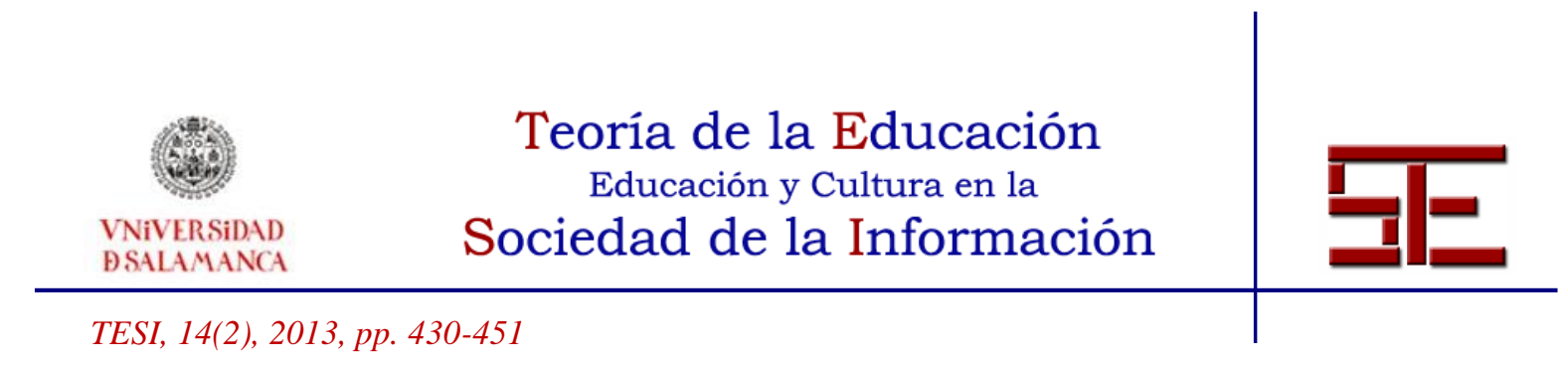

6.- ANEXO B - Resolução analítica (parcialmente correta) efetuada por um grupo

b. Calcule um IC a $95 \%$ para a $\%$ de alunos que obtém mais de 70 pontos. Resolução:

1. Considere-se o acontecimento, $X: \begin{cases}1 & \text { se o aluno obtém mais de } 70 \text { pontos } \\ 0 & \text { caso contrário }\end{cases}$ Temos que: $X \sim B_{e}(p)$

$p=P(X=1)$

(é o parâmetro desconhecido na população - \% de alunos que obtém mais de 70 pontos)

2. Amostra: $n=60$, entyo $\bar{X}=\hat{p}=\frac{27}{60}$

(pretendemos obter uma estimativa intervalar para $p$ ao nível de significância de $5 \%$ )

3. $\quad Z_{0}=\frac{\hat{p}-p}{\sqrt{\frac{p(1-p)}{n}}} \sim N(0,1)$
$\left(Z_{c}=\phi^{-1}(0975)=1.9599 \approx 1.96\right)$

4. Construção do intervalo aleatório: $\left[-1.96 \prec \frac{\hat{p}-p}{\sqrt{\frac{p(1-p)}{n}}} \prec 1.96\right]$

( $p$ é o parâmetro a estimar; em $\sqrt{\frac{p(1-p)}{n}}$ substitui-se $p$ pela sua estimativa pontual $\hat{p}$ )

- Limites do intervalo aleatório: $] \hat{p}-1.96 \times \sqrt{\frac{\hat{p}(1-\hat{p})}{n}}, \hat{p}+1.96 \times \sqrt{\frac{\hat{p}(1-\hat{p})}{n}}[$

Utilizando a amostra para a estimativa intervalar, tem-se:

de alunos

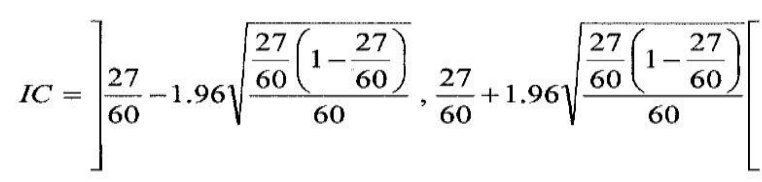

$\begin{array}{ll}\text { oeste modo, } & I C=\llbracket[0.32,0.58 \rrbracket \\ & I C=\llbracket 32 \%, 58 \% \rrbracket\end{array}$




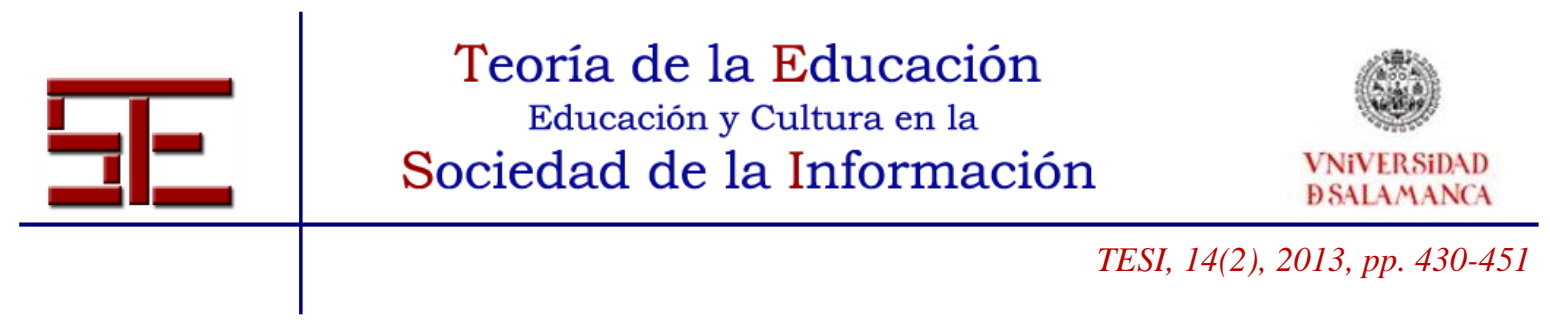

Para citar el presente artículo puede utilizar la siguiente referencia:

Gonçalves, G., Afonso, L., Ferreira, M., Ferro, T., Nascimento, M. M. (2013). A aprendizagem sobre intervalos de confiança com recurso ao software r. Revista Teoría de la Educación: Educación y Cultura en la Sociedad de la Información. 14(2), 430-450 [Fecha de consulta: dd/mm/aaaa].

http://campus.usal.es/ revistas_trabajo/index.php/revistatesi/article/view/10240/10672

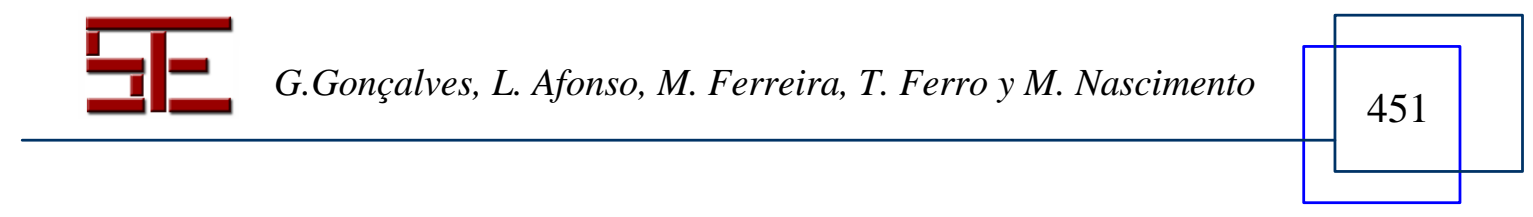

